\title{
Produtos de diferentes grupos químicos no controle da mancha branca do milho
}

\section{Products of different chemical groups to control maize white spot}

\author{
Eliseu dos Santos Pedro'; Ricardo Marcelo Gonçalves²; \\ Walter Fernandes Meirelles ${ }^{3}$; Luzia Doretto Paccola-Meirelles ${ }^{4 *}$
}

\section{Resumo}

O objetivo deste trabalho foi avaliar a eficiência de diferentes produtos no controle da mancha branca do milho, doença foliar causada pela bactéria Pantoea ananatis. Para o experimento foram utilizados seis produtos pertencentes a diferentes grupos químicos, testados no híbrido suscetível HS200. Avaliaramse as variáveis severidade, área abaixo da curva de progresso da doença (AACPD) e a produtividade de grãos. O tratamento com oxitetraciclina resultou maior produtividade de grãos da cultura do milho. Produtos naturais testados no experimento, como Rocksil e Ácido Pirolenhoso, utilizados como suplementos nutricionais para as plantas, não foram eficientes no controle da mancha branca do milho.

Palavras-chave: Zea mays L., controle químico, Pantoea ananatis, antibiótico

\begin{abstract}
The aim of this work was the evaluation of different products used to control maize white spot, a leaf disease caused by the bacterium Pantoea ananatis. Six products from different chemical groups were used for this experiment, and they were tested on the susceptible hybrid HS200. Parameters, such as severity (\%), area under disease progress curve (AUDPC), and productivity, have been estimated. The treatment with oxytetracycline resulted higher grain productivity for maize. Natural products, such as Rocksil and Pyroligneous acid, even though they are used as supplement for plants, were not effective in controlling the maize white spot.
\end{abstract}

Key words: Zea mays L., chemical control, Pantoea ananatis, antibiotic

\footnotetext{
${ }^{1}$ Discente em Engenharia Agronômica, Universidade Estadual de Londrina, UEL, Londrina, PR. E-mail: eliseupedro@hotmail.com

${ }^{2}$ Mestrando em Agronomia, UEL, Londrina, PR. E-mail: goncalves.agrouel@gmail.com

${ }^{3}$ Pesquisador da Embrapa Milho e Sorgo, Sete Lagoas, MG. E-mail: walter@cnpso.embrapa.br

${ }^{4}$ Prof $^{\mathrm{a}} \mathrm{Dr}^{\mathrm{a}}$ da UEL, Londrina, PR. E-mail: paccola@uel.br

* Autor para correspondência
} 
O milho (Zea mays) é um dos cereais mais cultivados no Brasil e no mundo. A área brasileira cultivada com a cultura, na safra de 2009/2010, correspondeu a 12,8 milhões de hectares, com uma produção de 56,1 milhões de toneladas (IBGE, 2011). A expansão das áreas cultivadas com a cultura do milho no Brasil, a extensão das épocas de cultivo e a utilização de cultivares precoces com maior potencial de produção, algumas vezes mais suscetíveis às doenças, têm contribuído para o aumento de doenças foliares na cultura (COSTA et al., 2008). Entre essas doenças merece destaque a mancha branca do milho (MBM). Os sintomas da MBM tem início com o aparecimento de manchas foliares de formato irregular, coloração verde escuro, aquosa do tipo anasarca, com aspecto de encharcamento. Posteriormente as lesões tornamse necróticas de coloração palha, podendo ocorrer coalescência das lesões. Os sintomas podem apresentar-se em diferentes severidades conforme o genótipo do milho (PACCOLA-MEIRELLES et al., 2002). De acordo com Sawazaki et al. (1997), em condições de chuvas frequentes e bem distribuídas, o patógeno pode provocar maior severidade e afetar drasticamente a produtividade.

A doença foi descrita inicialmente como sendo causada pelo ascomiceto Phaeosphaeria maydis, porém trabalhos posteriores descreveram a bactéria Pantoea ananatis como sendo o agente causal da doença (PACCOLA-MEIRELLES et al., 2001; BOMFETI et al., 2008). Produtos químicos comerciais já foram testados in vivo e in vitro para controle da MBM, sendo o Mancozeb o único produto que controlou eficientemente a bactéria in vitro e em condições de campo, sendo uma evidência adicional de que a doença é causada por uma bactéria (BOMFETI et al., 2007).

$\mathrm{Na}$ literatura estão descritas como principal medida de controle da doença a utilização de cultivares resistentes. Com relação à herança da resistência, têm sido relatados efeitos gênicos aditivos com alta herdabilidade (LOPES et al., 2007). Outras medidas como a rotação e semeaduras escalonadas, também são recomendadas. Tais medidas são muitas vezes suficientes; porém em regiões e/ou épocas em que se utilizam cultivares suscetíveis, as condições ambientais são favoráveis à doença e há elevado potencial de inóculo, podem ocorrer epidemias, sendo necessária intervenção com o uso de produtos químicos (ROLIM et al., 2007).

Para o controle da MBM estão registrados junto ao Ministério da Agricultura produtos químicos pertencentes a grupos como: triazóis, estrobilurinas, benzimidazóis, geralmente eficientes no controle de doenças fúngicas. Sabendo ser a bactéria $P$. ananatis o agente causal da MBM, têm-se a necessidade da busca por novas medidas de controle. Este trabalho teve como objetivo avaliar a eficiência a campo de produtos oxitetraciclina, Rocksil, tebuconazol, ácido pirolenhoso e cloreto de benzalcônico no controle da MBM.

$\mathrm{O}$ experimento foi instalado no ano agrícola de 2009/2010, no município de Londrina-PR, em área experimental da Embrapa Soja. As condições climáticas durante o ano agrícola foram temperatura máxima média de $28,2{ }^{\circ} \mathrm{C}$ e mínima média de $17,2{ }^{\circ} \mathrm{C}$ e precipitação de $2198,4 \mathrm{~mm}$. Testou-se a eficiência a campo de seis tratamentos, sendo eles: cloreto de benzalcônio (300 ml/100L/ha), tebuconazol (1L/200L/ha), oxitetraciclina (3Kg/ ha), Rocksil (1Kg/ha), Ácido Pirolenhoso (1L/ha) e água como testemunha. A composição do composto de terra mineral Rocksil é 20,56\% de $\mathrm{Al}_{2} \mathrm{O}_{3} ; 17,43 \%$ de $\mathrm{SiO}_{2} ; 9,82 \%$ de $\mathrm{S} ; 1,31 \%$ de $\mathrm{CaO} ; 0,34 \%$ de $\mathrm{TiO}_{2}$; $0,18 \%$ de $\mathrm{MgO} ; 0,16 \%$ de $\mathrm{Fe}_{2} \mathrm{O}_{3}$ e $0,10 \%$ de $\mathrm{P}_{2} \mathrm{O}_{5}$. O híbrido utilizado foi o HS200, reconhecidamente suscetível à mancha branca do milho.

Foram realizadas três aplicações de cada tratamento em um intervalo de 30 dias entre cada aplicação, sendo a primeira realizada 30 dias após a emergência (DAE) das plantas, com o auxílio de um pulverizador costal em alto volume pressurizado com gás carbônico, composto por uma barra de alumínio com quatro bicos anti-gotejantes do tipo leque espaçados, $50 \mathrm{~cm}$ entre eles. 
O delineamento experimental utilizado foi em blocos casualizados com três repetições e seis tratamentos, totalizando 18 parcelas. As parcelas foram constituídas por quatro fileiras $(4,0 \mathrm{~m}$ de comprimento) espaçadas em $0,8 \mathrm{~m}$ entre si, com uma área útil composta pelas duas fileiras centrais.

Estimou-se a severidade da doença, utilizando uma escala de notas variando de 1 a 6 , sendo: $1=$ sem lesões; 2 = lesões esparsas na planta; 3 = até $50 \%$ das folhas com lesões; $4=$ até $75 \%$ das folhas com lesões; $5=100 \%$ das folhas com lesões; 6 = seca total da planta. Ao todo foram realizadas quatro avaliações em intervalos de sete dias, sendo a primeira realizada 75 DAE. A produtividade de grãos foi determinada pela pesagem dos grãos de milho colhidos apenas na área útil de cada respectivo tratamento.

Com os dados de severidade da doença ao longo do tempo, calculou-se a área abaixo da curva de progresso da doença (AACPD). Os dados de AACPD, severidade média e produtividade de grãos foram submetidos a uma análise de variância, utilizando o teste de Scott-Knott a 5\% de probabilidade.

Para as variáveis severidade média da doença e AACPD, não houve diferença significativa entre os tratamentos (Tabela 1).

Tabela 1. Severidade média, Área Abaixo da Curva de Progresso da Doença e produtividade (Kg/ha) do híbrido HS200, após aplicação de diferentes tratamentos no controle da Mancha Branca do Milho.

\begin{tabular}{cccc}
\hline Tratamento & Severidade média $^{\mathbf{1}}$ & AACPD $^{\mathbf{2}}$ & Produtividade $^{\text {Oxitetraciclina }}$ \\
Rocksil & $2,14 \mathrm{a}$ & $50,96 \mathrm{a}$ & $8457,8 \mathrm{a}$ \\
Folicur - Tebuconazol & $2,37 \mathrm{a}$ & $55,94 \mathrm{a}$ & $6829,7 \mathrm{~b}$ \\
Ác. Pirolenhoso & $2,23 \mathrm{a}$ & $51,75 \mathrm{a}$ & $7214,1 \mathrm{~b}$ \\
Cloreto de Benzalcônio & $2,44 \mathrm{a}$ & $61,84 \mathrm{a}$ & $6882,8 \mathrm{~b}$ \\
Testemunha & $2,26 \mathrm{a}$ & $53,64 \mathrm{a}$ & $7059,4 \mathrm{~b}$ \\
\hline
\end{tabular}

${ }^{1}$ Médias seguidas da mesma letra não diferem estatisticamente pelo teste Scott-Knott a 5\% de probabilidade ${ }^{2}$ Área Abaixo da Curva de Progresso da Doença

Fonte: Elaboração dos autores.

A eficiência da oxitetraciclina em controlar outras doenças bacterianas vegetais tem sido apontada por outros autores (THEODORO; MARINGONI, 2000). Produtos sistêmicos como oxitetraciclina, quando pulverizados na parte aérea das plantas, são absorvidos e redistribuídos por todo o limbo foliar atingido, potencializando assim a sua ação.

Os tratamentos com Rocksil e Ácido Pirolenhoso também não se mostraram eficientes no controle de $P$. ananatis. Rocksil, também conhecido como "Pó de Rocha", tem seu uso principalmente como biofertilizante (OLIVEIRA et al., 2010). Plantas bem nutridas, geralmente apresentam maior tolerância ao ataque de pragas e patógenos, apesar disso, este fato não pode ser observado no estudo em questão, quando se analisou o efeito sobre $P$. ananatis.

O extrato pirolenhoso, também conhecido como ácido pirolenhoso, líquido pirolenhoso ou vinagre de madeira, é um líquido resultante da condensação da fumaça originada da fabricação de carvão (ALVES et al., 2007). Quando filtrado, após a decantação, este produto é composto de 80 a $90 \%$ de água e 10 a $20 \%$ de compostos orgânicos, sendo o principal o ácido acético. Segundo Maekawa (2002), quando aplicado em diluições de 300 a 600 vezes, apresentase promissor no controle de pragas e doenças, podendo ser aplicado isoladamente ou misturado 
com outros extratos de plantas. Entretanto no presente trabalho o extrato pirolenhoso não mostrou eficiência no controle da mancha branca do milho.

Quando se analisa a produtividade, somente o tratamento com a oxitetraciclina se mostrou diferente estatisticamente dos demais, resultando em maior produção (Tabela 1). Apesar de não ter inibido estatisticamente o desenvolvimento da mancha branca do milho, se mostrou responsável por um acréscimo de mais de 19\% na produtividade.

Com isso, os produtos naturais testados nesta pesquisa, como Rocksil e Ácido Pirolenhoso, não apresentaram eficiência no controle da MBM, e o tratamento com oxitetraciclina, foi o único que resultou maior produtividade de grãos de milho.

\section{Referências}

ALVES, M.; CAZETTA, J. O.; NUNES, M. A.; OLIVEIRA, A. L. O.; COLOMBI, C. A. Ação de diferentes preparações de extrato pirolenhoso sobre Brevipalpus phoenicis (GEIJSKES). Revista Brasileira de Fruticultura, Cruz das Almas, v. 29, n. 2, p. 382-385, 2007.

BOMFETI, C. A.; MEIRELLES, W. F.; SOUZAPACCOLA, E. A.; CASELA, C. R.; FERREIRA, A. S.; MARRIEL, I. E.; PACCOLA-MEIRELLES, L. D. Avaliação de produtos químicos comerciais, in vitro e in vivo, no controle da doença foliar, mancha branca do milho, causada por Pantoea ananatis. Summa Phytopathologica, Botucatu, v. 33, n. 1, p. 63-67, 2007.

BOMFETI, C.A.; SOUZA-PACCOLA, E.A.; MASSOLA JUNIOR, N. S.; MARRIEL, I. E.; MEIRELLES, W. F.; CASElA, C. R.; PACCOLA-MEIRELLES, L. D. Localization of Pantoea ananatis inside lesions of maize white spot disease using transmission electron microscopy and molecular techniques. Tropical Plant Pathology, Brasília, v. 33, n. 1, p. 63-66, 2008.

COSTA, F. M.; BARRETO, M.; KOSHIKUMO, E. S. M.; ALMEIDA, F. A. Progresso da ferrugem tropical do milho (Zea mays L.), sob diferentes tratamentos fungicidas. Summa Phytopathologica, Botucatu, v. 34, n. 3, p. 248-252, 2008.
INSTITUTO BRASILEIRO DE GEOGRAFIA E ESTATÍSTICA - IBGE. Levantamento sistemático da produção agrícola: confronto das safras de $2010 \mathrm{e}$ 2011 - Brasil. 2011. Disponível em: <http://www.ibge. gov.br/home/estatistica/indicadores/agropecuaria/lspa/ defaulttab.shtm>. Acesso em: 16 nov. 2011.

LOPES, M. T. G.; LOPES, R.; BRUNELLI, K. R., SILVA, H. P.; MATIELLO, R. R.; CAMARGO, L. E. A. Controle genético da resistência à mancha-de-Phaeosphaeria em milho. Ciência Rural, Santa Maria, v. 37, n. 3, p. 605$611,2007$.

MAEKAWA, K. Curso sobre produção de carvão, extrato pirolenhoso e seu uso na agricultura. Botucatu: APAN, 2002. mimeografado.

OLIVEIRA, M. C.; NETO, J. V.; OLIVEIRA, R. S.; PIO, R.; OLIVEIRA, N. C.; RAMOS, J. D. Enraizamento de estacas de duas cultivares de oliveira submetidas à aplicação de diferentes fertilizantes. Bragantia, Campinas, v. 69, n. 1, p. 99-103, 2010.

PACCOLA-MEIRELLES, L. D.; FERREIRA, A. S.; MEIRELLES, W. F.; MARRIEL, I. E.; CASELA, C. R. Detection of a bacterium associated with a leaf spot disease of maize in Brazil. Journal of Phytopathology, Berlin, v. 149, n. 5, p. 275-279, 2001.

PACCOLA-MEIRELLES, L. D.; MEIRELLES, W. F.; PARENTONI, S. N.; MARRIEL, I. E.; FERREIRA, A. S.; CASELA, C. R. Reaction of maize inbred lines to the bacterium Pantoea ananas isolated from Phaeosphaeria leaf spot lesions. Crop Breeding and Applied Biotechnology, v. 2, n. 4, p. 578-590, 2002.

ROLIM, G. S.; PEDRO JÚNIOR, M. J.; FANTIN, G. M.; BRUNINI, O.; DUARTE, A. P.; DUDIENAS, C. Modelo agrometeorológico regional para estimativa da severidade da mancha de Phaeosphaeria em milho safrinha no Estado de São Paulo, Brasil. Bragantia, Campinas, v. 66, n. 4, p. 721-728, 2007.

SAWAZAKI, E.; DUDIENAS, C.; PATERNIANI, M. E. A. G. Z.; GALVÃO, J. C. C.; CASTRO, J. L.; PEREIRA, J. Reação de cultivares de milho à mancha de Phaeosphaeria no estado de São Paulo. Pesquisa Agropecuária Brasileira, Brasília, v. 32, n. 6, p. 585-589, 1997.

THEODORO, G. F.; MARINGONI, A. C. Ação de produtos químicos in vitro e in vivo sobre Clavibacter michiganensis subsp. michiganensis agente causal do cancro bacteriano do tomateiro. Scientia Agricola, Piracicaba, v. 57, n. 3, p. 439-443, 2000. 